LA-8337-MS

Informal Report

UC-4

Issued: August 1980

Nuclear-Radiation Measurement Facilities at the

Radiochemistry Laboratory at LASL

\author{
J. P. Balagna
}
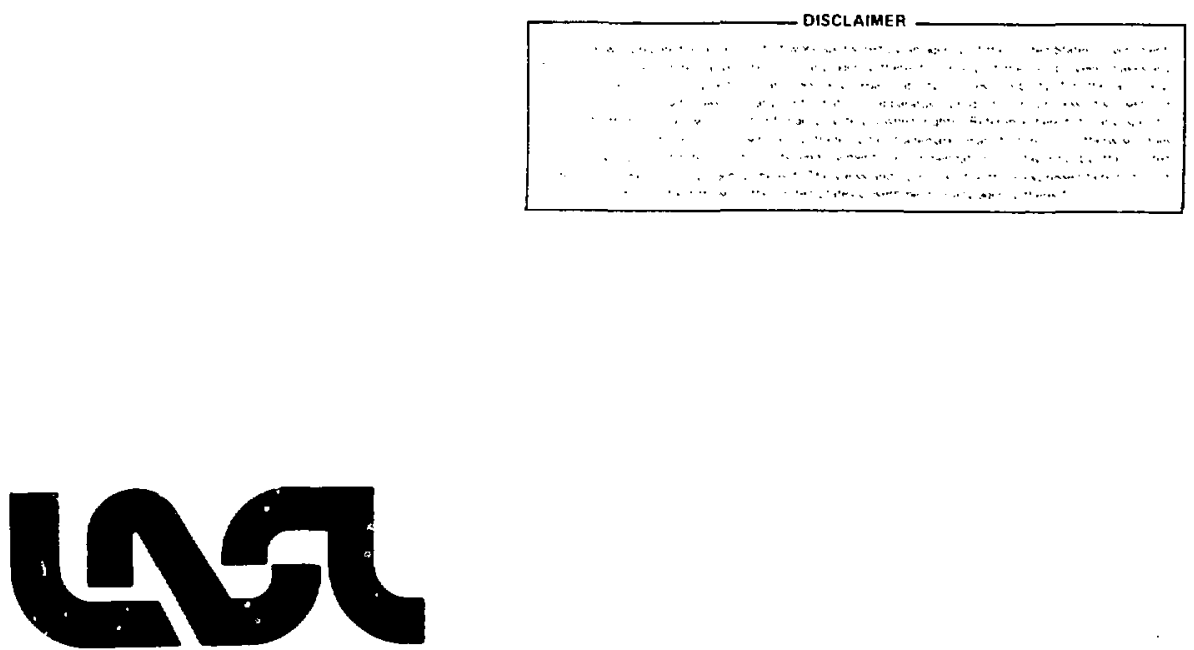


\title{
NUCLEAR-RADIATION MEASUREMENT FAC!ITIES AT THE RADIOCHEMISTRY LABORATORY AT LASL
}

\author{
by
}

\author{
J. P. Balagna
}

\begin{abstract}
A brief description is given of the radiation counting facilities and different types of systems used by the CNC-11 radiochemistry group at the Los Alamos Scientific Laboratory.
\end{abstract}

\section{INTRODUCTION}

The radiochemistry laboratory was placed in operation in 1948 to measure fission-product nuclides from the Sandstone series of that year. Since that time, it has evolved as the needs of (iroup C.NC-11 have changed and expanded. Today any nuclear radiation except the neutrino can be measured in a reproducible and quantitative fashion. The use of Geiger counters was abandoned in late 1948 because of their unpredictable life and poor reproducibility.

\section{ALPHA COUNTING}

The quantitative measurement of alpha radioactivity ${ }^{239} \mathrm{Pu}$ was originally done using parallel-plate ionization chambers in which $\mathrm{N}_{2}$ was the working gas. When Group CMB- $\tau$ made gas proportional counters reliable in 1949, we put in service a design useful for alpha counting. However, this model gave poor operational experience in the presence of highbeta samples and low-level samples from ion exchange columns. Thus, we returned to using ion chambers in 1976.

Our alpha counters have been stable to within $1 \%$ from installation in 1949 to the present. Now we are operating five units, three of which can also measure spontaneous fission decay while counting alpha activity. The working gas presently used is propane because this gas is conveniently available.

Absolute calibration of these counters has been done by three methods. Originally the geometry was determined by calibrating a ${ }^{210} \mathrm{Po}$ solution with a microcalorimeter and then counting an aliquot in the alpha counters. This gave a geometry factor of $51.65 \%$ of $4 \pi \pm 1 \%$. In 1965. a calibration using ${ }^{2 " A m}$ that was standardized by $4 \pi$ alpha, gamma counting gave a geometry value of $51.75 \% \pm 0.75 \%$. In 197 (1) a calibration using ${ }^{241} \mathrm{Am}$ that was stan. dardized in a low-geometry counter gave a value of $51.720 .1 \%$.

These counting systems have never been automated for data acquisition because the amount of counting done has never been large.

\section{II. BETA COUNTING}

The original beta counters were Geiger counters (Eck \& Krebs* glass tubes). Operation was erratic and of limited life. In 1949, they were replaced with

- Hek \& Krebs Scientific Laboratory Glass Apparatus Inc. Long Island (ity SY 11101 . 
methane-flow proportional counters designed and built at the Los Alamos Scientific Laboratory by Group CMB-T.* Radioactive standards of ${ }^{239} \mathrm{U}$ and its daughter products were made to follow counter performance. The counters were calibrated absolutely to determine fissions in ${ }^{285} \mathrm{U}$ by comparison fission counting and chemical separation of ${ }^{\circ} \mathrm{Mo}$ for het a counting. Stability of these counters has been very good lless than $1 \%$ drift in counting rate on one unit (Fig. 1 ) from 1950) to the present|. Deadtime corrections have always been included in computa. tions of dat a from these counters. In 1966, the working gas was changed from methane to propane hecause the uperational voltage plateaus were better tsee ser. Xll. BI.

In $195 \%$, the workload for beta counting had in(reased (1) a level where automation was necessary. A whe lsistem was designed for entering the input data previnusly being entered manually (Fig. 2). When completed in 1962, the system had nine autumatic changers in operation. Data recording is dune un an IB.S 526 summary Punch** (Fig. 3).

\section{GAMMA COLNTING}

The serious use of Vall Th detectors for gammaras measurement hegan about 1950 . However. counting rate stability was a problem. Only after transistorized pulse-height analyzers were developed was reliable gamma counting possible.

\section{POSITRON COUNTING}

The problem of measuring radioactive nuclides that are neutron deficient in the presence of betaemitting fission products, such as the pair ${ }^{*} \mathrm{Zr}$ - ${ }^{*} \mathrm{Zr}$. was solved by using a trochoidal analyzer, which uses a shaped magnetic field to separate positrons from negatrons (Fig. 4). Two such units, now in operation. have an absolute efficiency of $10 \%$ of $4 \pi$ and a separation factor between positrons and negat rons of $110^{\circ}$.

\footnotetext{
-1)ne if thent mudels was later erroneously called the Sugarman inumer

-Internatlunal Buness Machines, Armonk, XY 01504
}

\section{LOW-BACKGROUND BETA COUNTING}

The cosmic-ray flux, which causes background in beta counters, is twice the rate at $7200 \mathrm{ft}$ (altitude) that it is at sea level. As a result, measuring lowactivity samples requires some type of active shielding. We have developed a system (Fig. 5) that gives a geometry equivalent to our other betacounting systems and has a background a factor of 100 lower than that of other counters 10.2 counts $/ \mathrm{min}$ ).

\section{SPECTROSCOPY}

The advent of solid-state circuitry for multichannel analyzers (MCAs) and analog electronics fabrication made spectroscopy usable on a routine basis.

\section{ALPHA SPECTROSCOPY}

The performance of the Frisch-grid ion chamber for the measurement of both energy and intensity of alpha-particle sources still cannot be matched. The geometry of this detector is high $(50 \%)$. its stability is good, and the background is less than that for any other particle detector $(0.001$ counts $/ \mathrm{min}$ per channel) (Fig. 6)

Where the ratio of two or more alpha-emitting species of different energies is required, the surfaceharrier silicon detestor is adequate. Both the ion chamber and silicon detector are in use here. Energy resolution is about the same for both types. All alpha-spectroscopy systems can measure the spontaneous fission rate of a sample while performing alpha spect roscopy.

\section{X. GAMMA SPECTROSCOPY}

\section{A. $\mathrm{NaI}(\mathrm{Tl})$}

These detectors. mostly the well type, are used to measure a radioactive nuclide or nuclides after extensive chemistry on a sample eliminates all but one chemical species o: after additional work with a 
mass separator provides a radicactive sample containing only one radioactive nuclide (for example ${ }^{17} \mathrm{Lu}$. They are used with an MCA and readout sustem connected to a midicomputer for data analysis (Figs. $7-9$ ). The high efficiency and longterm stability and reliability of Nal(Tl) detectors lend themselves very well to problems of gamma-ray neasurement.

\section{B. Ge(Li)}

The high-energy resolution of these devices makes them useful where little or no chemistry has been done on a sample. They are also useful where more than one nuclide must he measured in a mixture of isotopes. A special application of these detectors is the anitcoincident-shielded well counter where high efficiency, low background, and compton suppression all contribute to increased sensitivity of the detector swstem (Figs. 10 and 111 .

\section{LOW-LEVEL GAS PROPORTIONAL (O) NTING}

The use ul $2-\ell$ fas counters for moasuring lowenergy heta or $\mathrm{x}$-ray emissions, such as 'H.' $('$. or Ar, is a very specialized form of radiation measurement. Elaborate active and passive shielding is re. quired in achieve state-of the-art results. He have three such sustems in operation with the required gas chemistry separation systems (Fig. 12).

\section{AUTOMATION}

\section{A. Automation of Gamma Spectroscopy}

At present, seven computer-controlled sample changing sustems are in operation with $(i e(L i)$ detectors. These linits can be programmed to measure 24 samp'as each, at selected times with selected efficiencies, and do the required data reduciicn in the associated computers (Fig. 1:3 and 14). Automation of the well $\mathrm{Nal}$ system has begun: so far. one unit is fully automated (Fig. 15). All data collection from these systems is done by the pulse. height-analyzer readout (PHARO) system.

\section{B. Computer Utility}

The autounated data-collection system for alpha and ganma is served by a combination of computers. The system used until recently was a PDP-9 computer* with data transfer for plotting purposes t0 a PIPP-11/05 that ran two Calcomp plotters. ${ }^{* *} \mathrm{~A}$ back-up PDP-9 was also available to keep the sistem running 24 hours a day, 7 days a week.

Just recently, the PDP-9 has been transferred to back-up status, and the dat a acquisition and control system is now based on a PDP-11/60 computer. A transfer switch still allows use of either PDP-9 if necessary.

\section{Software and Data Reduction}

Our auiumatic readout sistem (PHARO) allows the compuier to read the dat a stored in a particular analyzer's memory and to read an accompanying series of digits from a panel of thumbwheel switches that identify the sample being counted. The com. puter stores the data in a file on a secondary storage medium and places this job in a queve of jobs to be processed

The processing of a spectrum consists of checking the data for possihle readout errors, checking the identification to determine which processing options are $t w$ be invoked, and then conrdinating the execution of these processing options. The options include a channel-by-channel listing, a plot, and magnetic tape storage. A particular user may prefer to give some special treatment to certain NaI spectra. Sitandards are examined very carefully. Certain paraneters are measured, depending on the type of standard, and compared against historical averages. A quality assurance number is printed out for the operator. (ie(Li) spectra may be analyzed by our inhouse gamma-ray spectrometry program called RAYCi' $Y$. It produces a list of peaks along with their net area. Then, by searching one of several small libraries. the program identifies a nuclide and estimates how much of it is in the sample. These estimates are then converted to disintegrations per

\footnotetext{
-1)gual Liqupment (irp. Maynard, MA 01754.

- Callurna Cimputer Products Ine. Anaheim, CA 92801.
} 
minute (DPM) at $\mathrm{T}_{0}$ for the identified nuclide based on known decay-scheme parameters and a predetermined efficiency curve for the particular detector and sample configuration. Table $I$ is an output listing from RAYGUN.

\section{QUALITY CONTROL OF ALL SYSTEMS}

\section{A. Introduction}

The procedures that follow are designed to control the quality of the data obtained in alpha and beta counting and in gamma and alpha spectroscopy. They insure that the various detectors behave consistently from day to day.

\section{B. Alpha Counting}

Uncovered ${ }^{230} \mathrm{Pu}$ standards (plutonium electroplated on platinum disks) and background are counted daily. If abnormal fluctuations in the count rate of the standard are observed, a "plateau" is run, or other special diagnostic procedures are applied.

\section{TABLE I}

\section{SAMPLE ANALYSIS FROM RAYGUN}

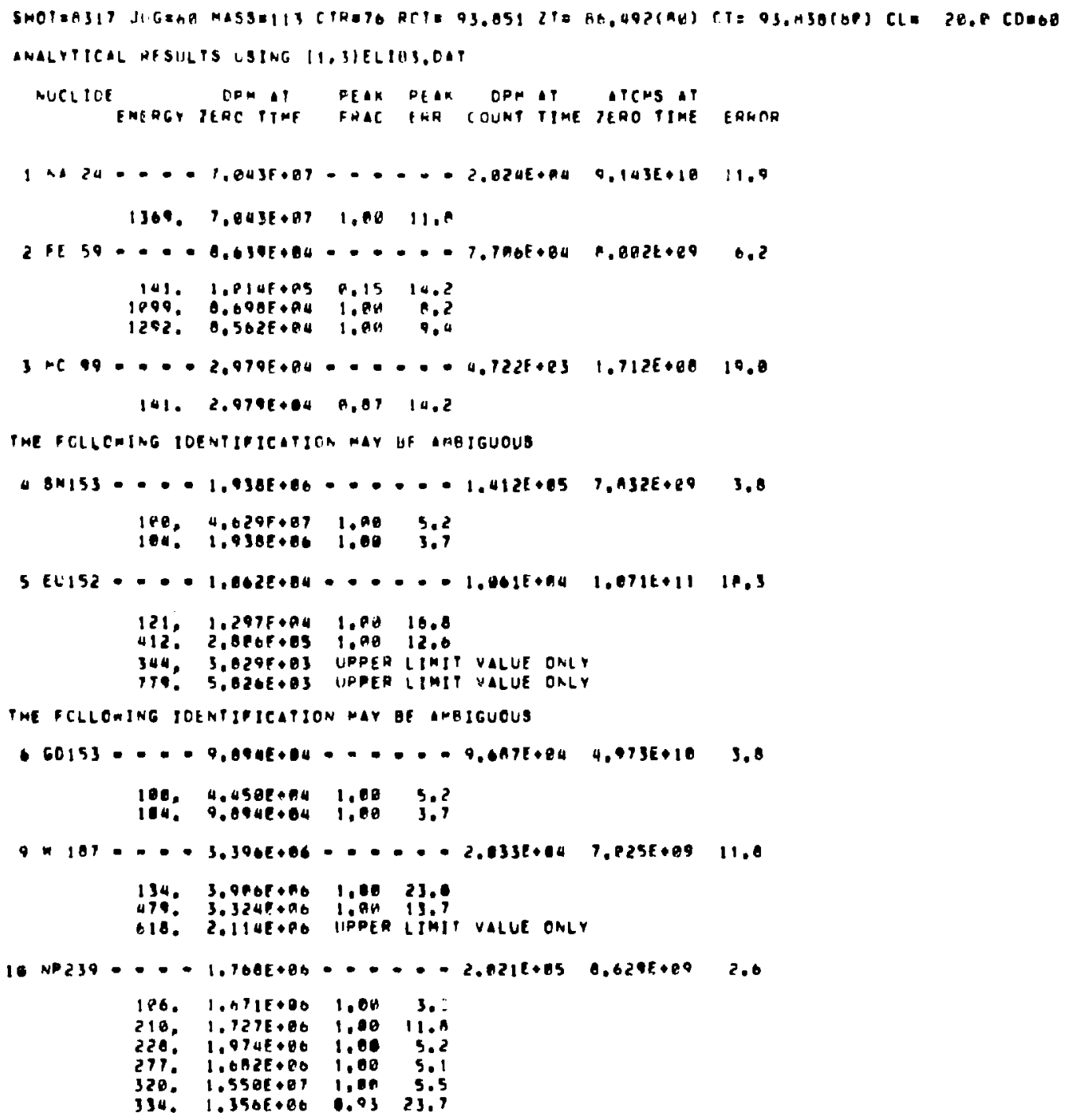


The plateau, which is determined once a week, is a plot of counting rates versus voltage applied to the central wire anode of the gas detector. From this measurement, we can determine whether overall gain (gas and electronic) has changed. The voltage is increased in $100-\mathrm{V}$ steps and a 5 -min count is taken at each step. We look for changes in the shape of the curve. If the plot shows abnormalities lexperience permits the ready recognition of abnormalities), proper maintenance steps are taken.

Once a month, a special ${ }^{239} \mathrm{Pu}$ standard is counted on every alpha counter. The decay rate of this standard is known absolutely, and if the counters are operating normally, they must give the correct counting rate. Any counter that does not give the correct count is repaired.

NOTE: In our laboratory, a mode of operation has been chosen that accepts standard deviation limits of \pm 1.5 as normal statistical variation. If the fluctuations in count rate exceed these limits, a second count is taken; normal limits for this determination are \pm 3.0 standard deviations.

\section{Beta Counting}

Daily counts of a ${ }^{234} \mathrm{~Pa}\left(\mathrm{U}_{3} \mathrm{O}_{3}\right.$ source) st andard and hackground are taken. Except for the fact that no mont hly absolute standard count is made, what applies to alpha counting applies here.

\section{Gamma Spectroscopy}

MCAs with two types of detectors, $\mathrm{NaI}$ and $\mathrm{Ge}(\mathrm{L}, \mathrm{i})$, are used for gamma spectroscopy.

1. NaI Detectors. To determine whether the analyzers are operating consistently, ${ }^{197} \mathrm{Cs}$ standards and background are counted daily. The electronic gain of the system (energy span) is adjusted to place the photopeak of the standard in a specific channel. If, on any day, the electronic gain settings for the standard are different from those of the previous day, then the system is examined to determine the reason for the anomalous behavior.
Each day, total counts under the photopeak of the standard are determined. If the system is operating consistently, the number of counts should be approximately the same from day to day. The same statistical considerations are applied as for alpha and beta counting.

2. $\operatorname{Ge}(\mathrm{Li})$ Detectors. Standard and background counts are made daily. For these detectors, the standard is ${ }^{182} \mathrm{Eu}$. The elect ronic gain of the system is adjusted and checked in the same manner as for $\mathrm{NaI}$ detectors.

Two optinns are available for the absolute calibration of the detectors for intensities versus energies of gamma rays. One makes use of a source of mixed radionuclides obtained from National Bureau of Standards. This source provides absoluely known gamma-ray intensities for calibration purposes. The second option uses an intensity-calibrated ${ }^{102} \mathrm{Eu}$ st andard (also supplied by the National Bureau of Standards). The serond option is preferable because the single nuclide decays with the same long half-life (the standards can be used for many years) whereas some of the nuclides in the mixed standard have short half-lives (new standards must be obtained vearly).

Deviations in the positions, intensities, and full width at half maximum (energy resolution) are monitored for abnormal fluctuations.

\section{E. Alpha Spectroscopy}

Two types of spectrometers with MCAs are used for alpha spectroscopy: Frisch grid and silicon diode. Background counts and the alpha spectrum of a mixed ${ }^{230} \mathrm{Pu}$ and ${ }^{230} \mathrm{Pu}$ standard are taken daily. The import ant quality control parameters in alpha spectroscopy are (1) the full width at half maximum of the alpha-particle full-energy peaki, (2) the ratio of the full-eriergy peak integrals of the ${ }^{350} \mathrm{Pu}$ and the ${ }^{238} \mathrm{Pu}$, and (3) the absolute intensity of the ${ }^{230} \mathrm{Pu}$ in. tegral. These parameters are monitored daily for abnormal statistical fluctuations, which indicate that maintenance is necessary. 


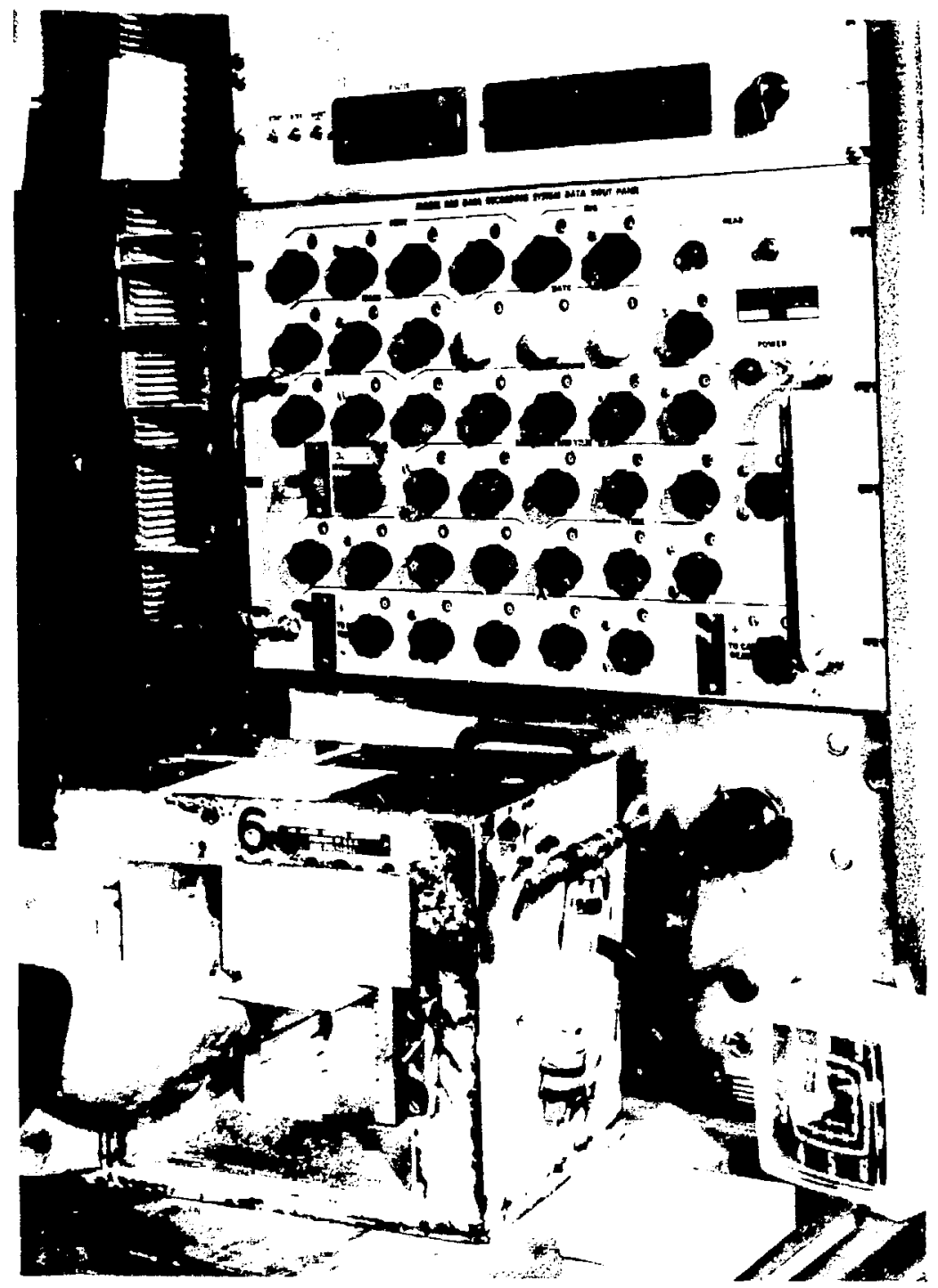

Fig. 1.

Beta counter and readout.

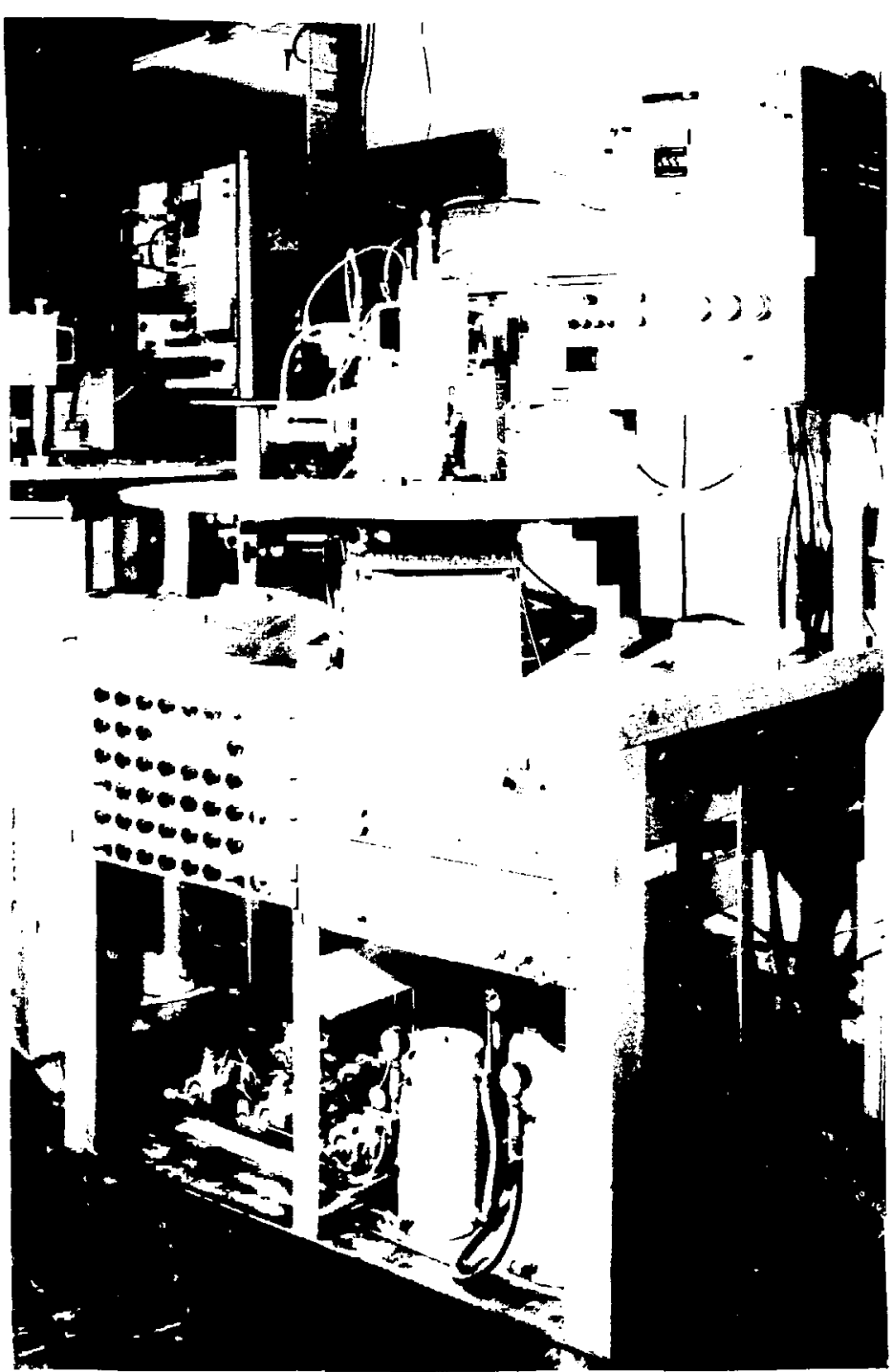

Fig. $2 a$.

Automatic beta counter. 


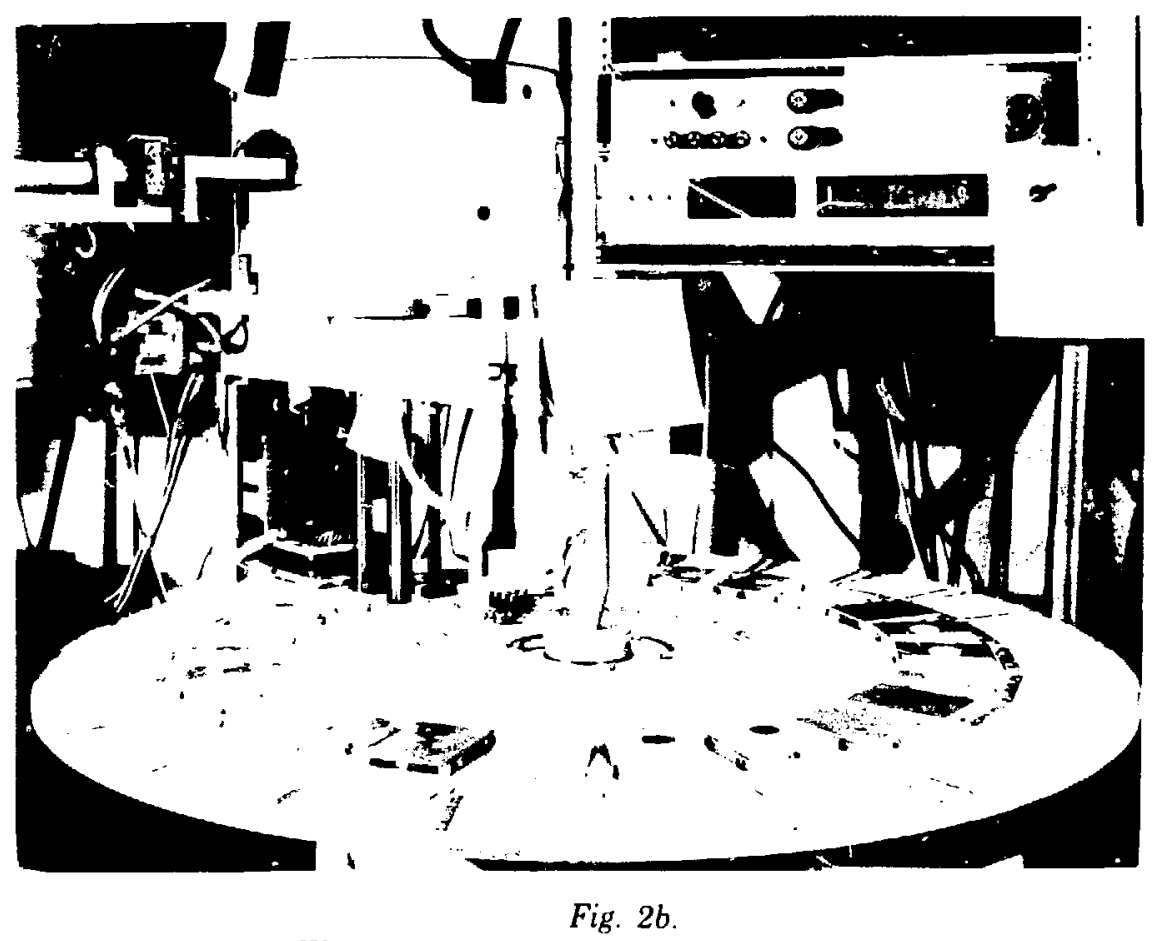

Wheel carrying samples on the beta counter.

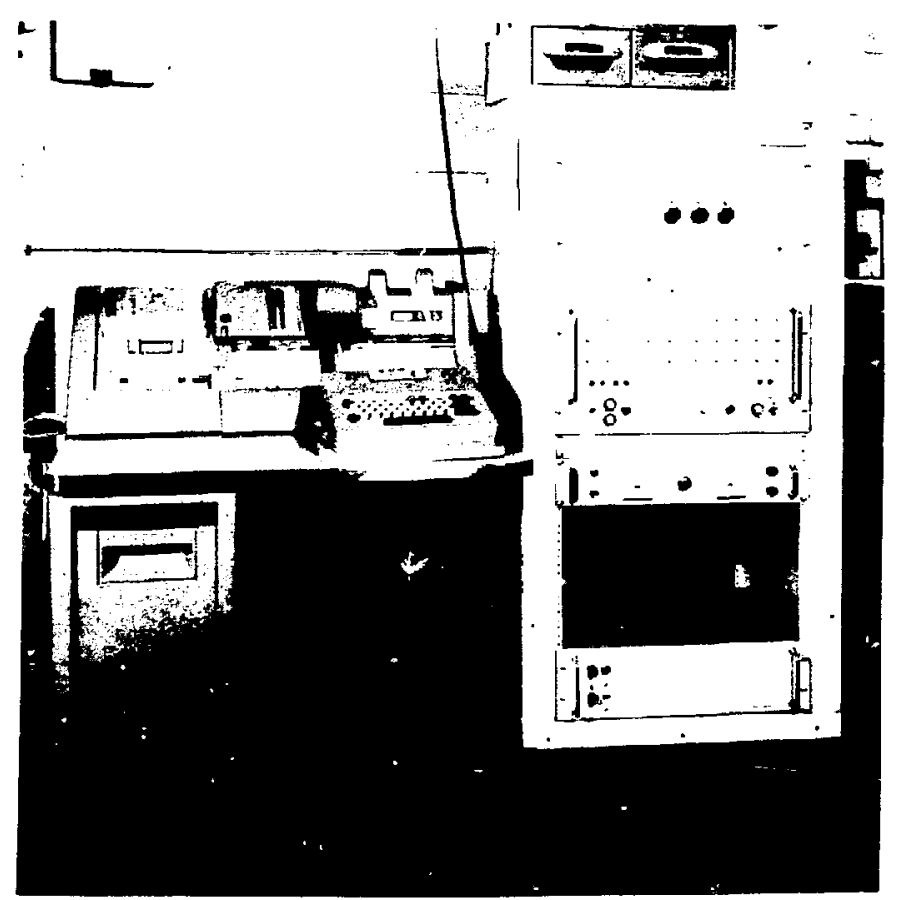

Fig. 3.

Card punch and multiplixer for the automatic betacounting system. 


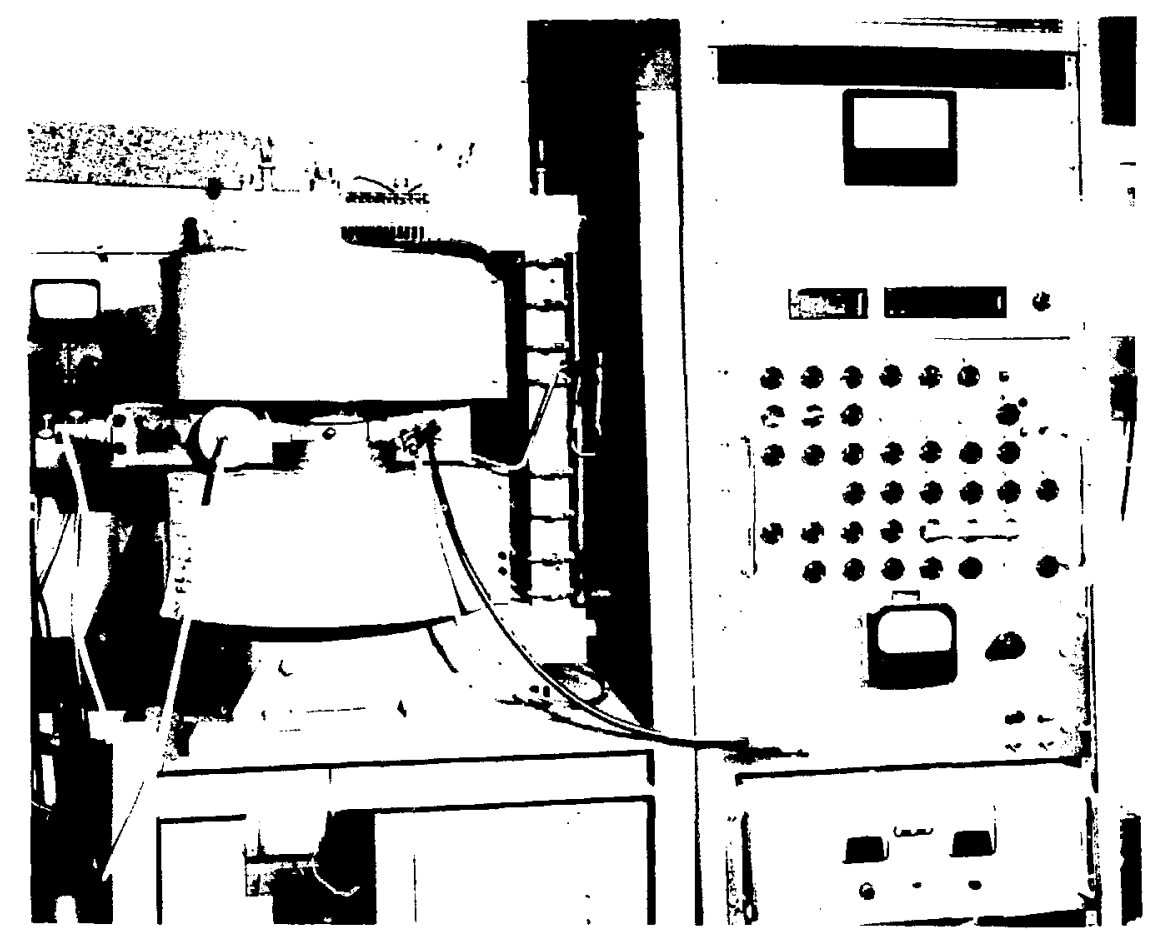

Fig. 4.

Trochoidal analyzer and readout.

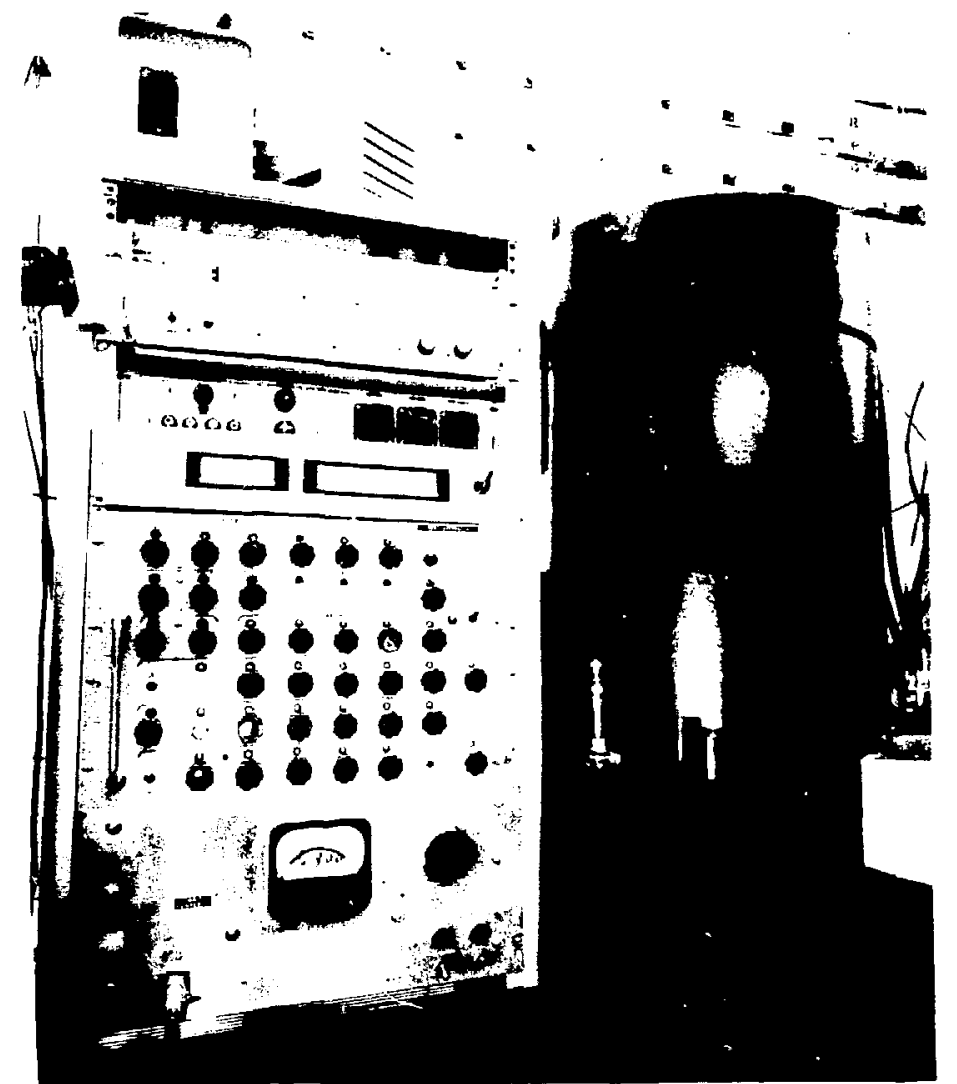

Fig. $5 a$.

Ultralow-level beta counter and readout. 


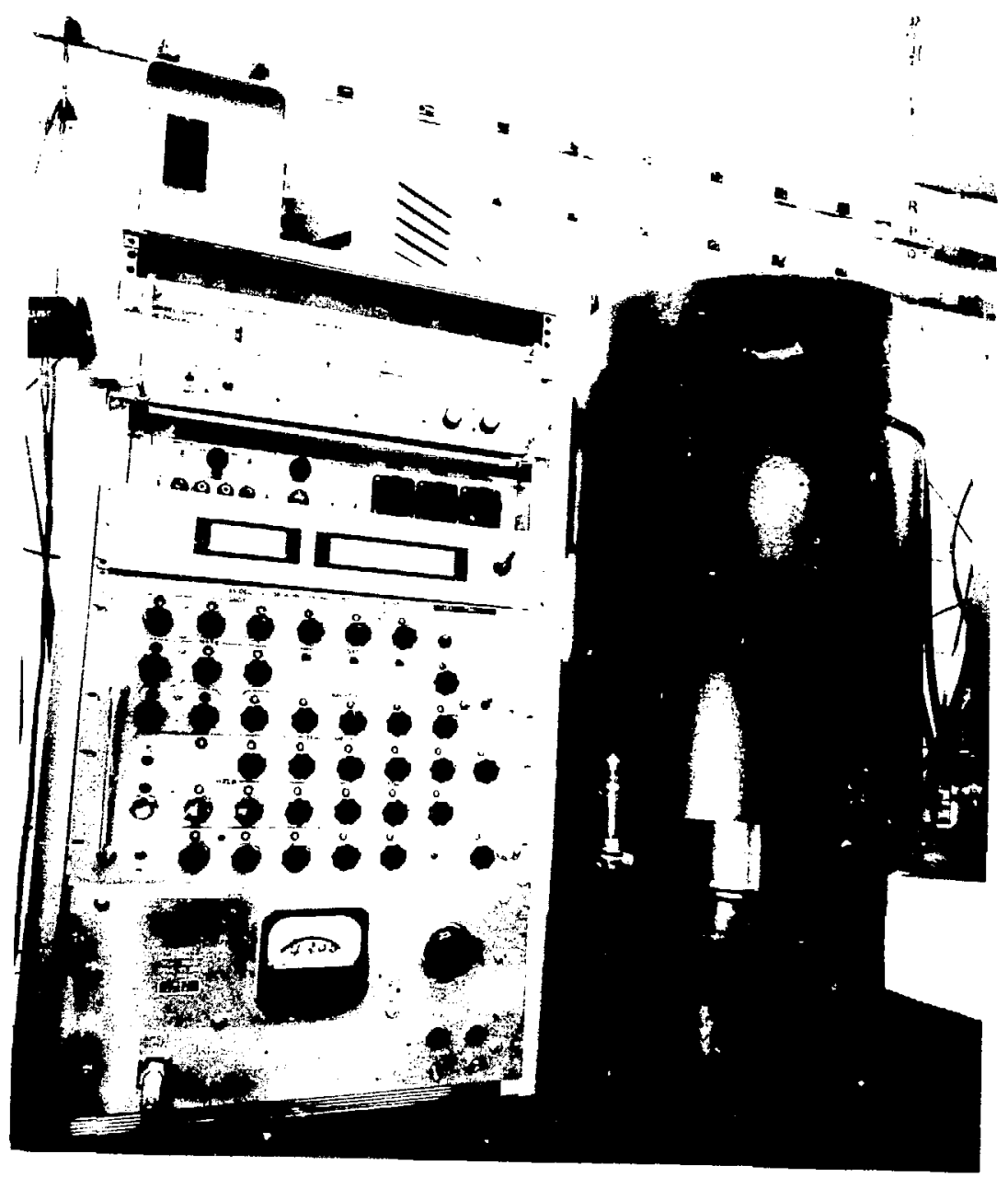

Fig. $5 b$.

Ultralow background counter, anticoincidence shield in place.

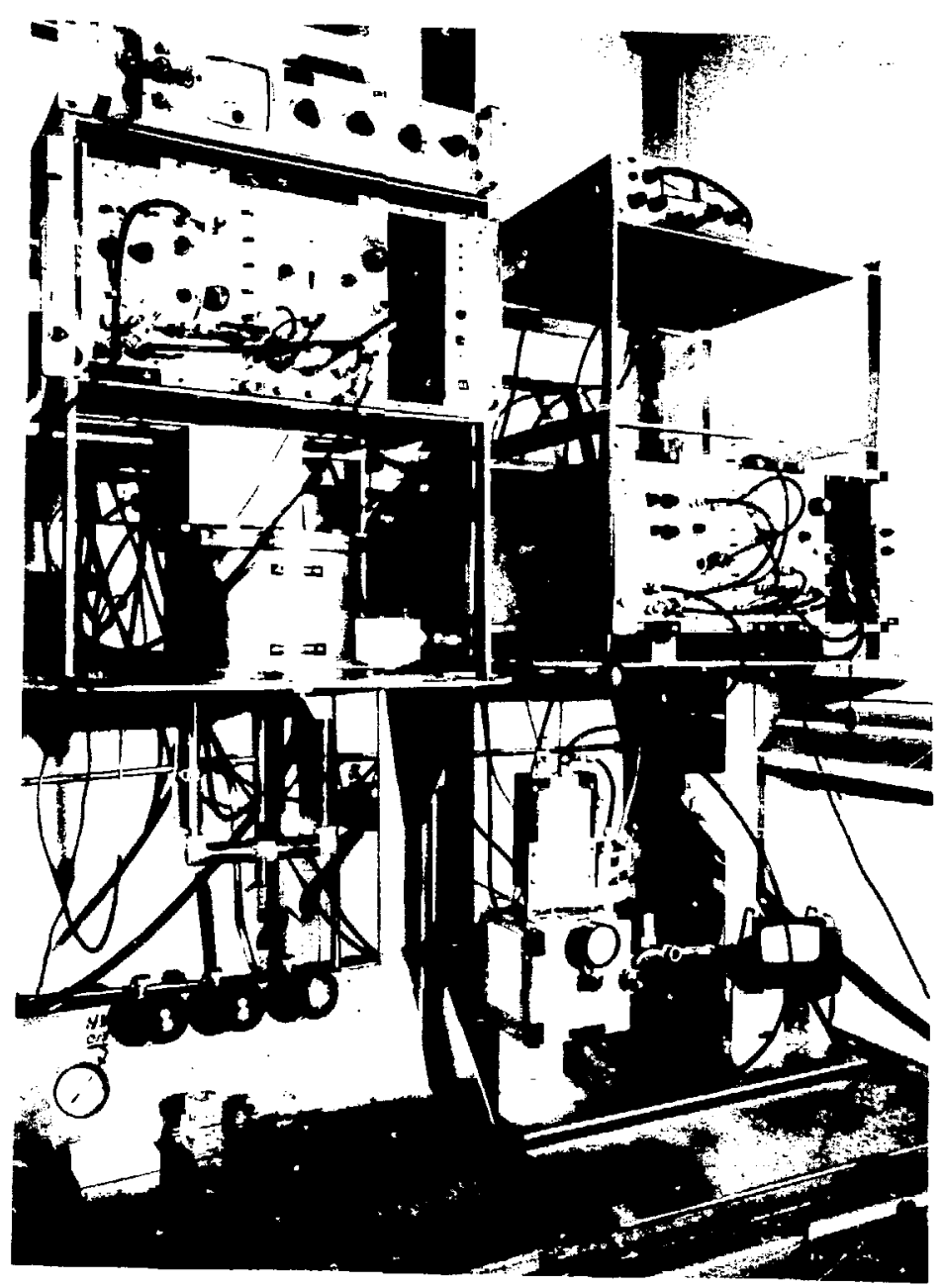

Fig. 6.

Frisch-grid and surface-barrier alpha spectrometers. 


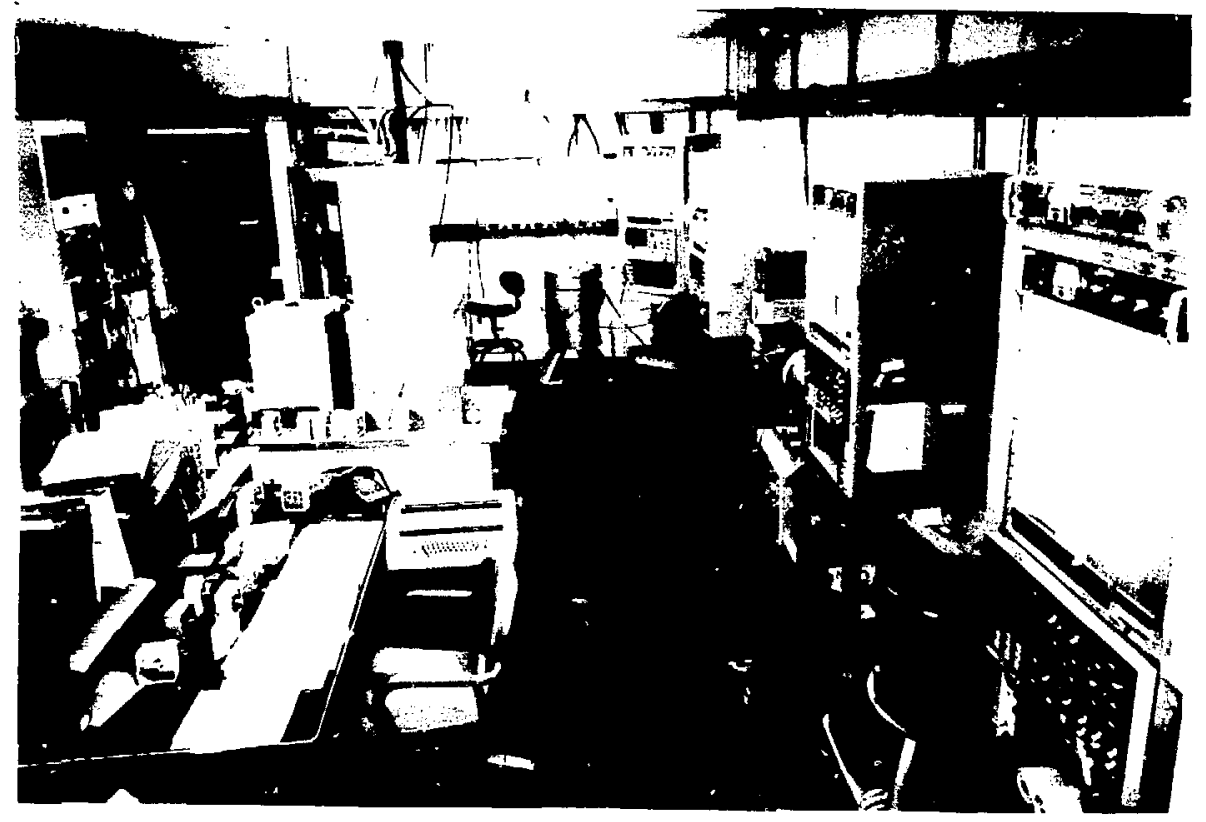

Fig. 7.

NaI gamma-spectroscopy laboratory.

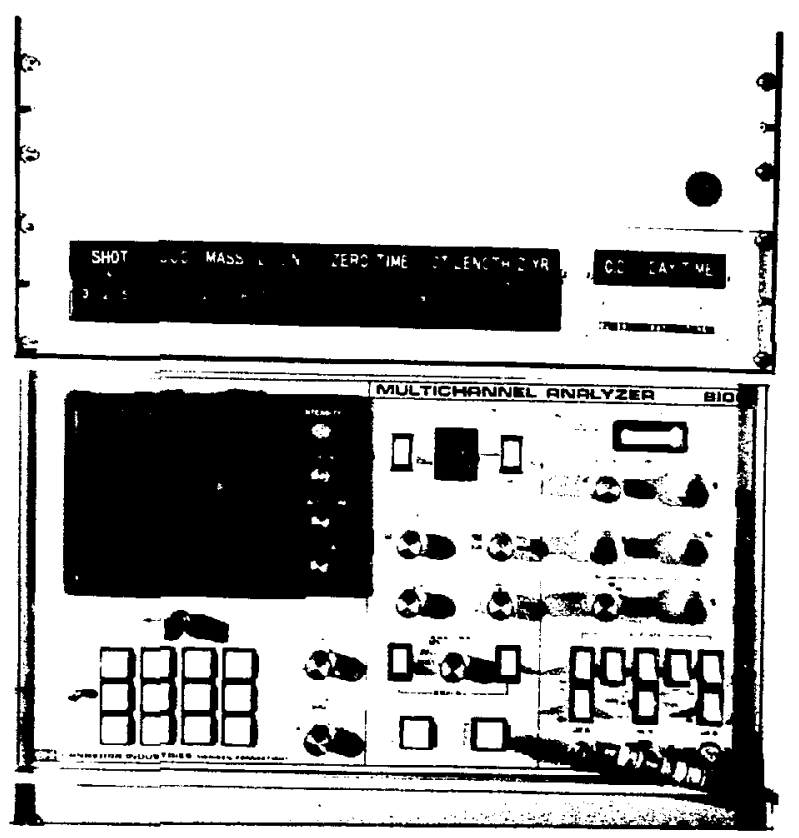

Fig. 8.

Pulse-height analyzer and readout (PHARO) system for spectroscopy. 


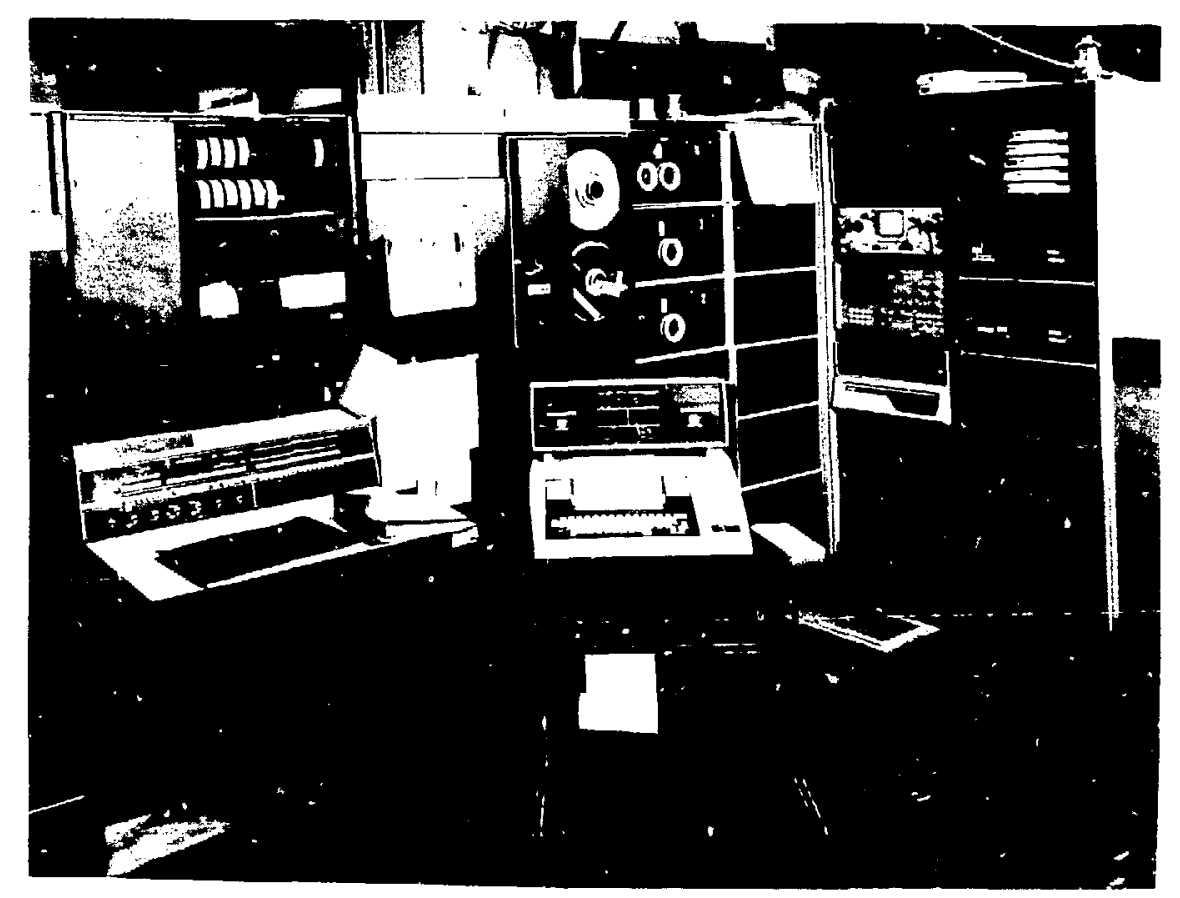

Fig. 9.

Computer for data acquisition and processing.

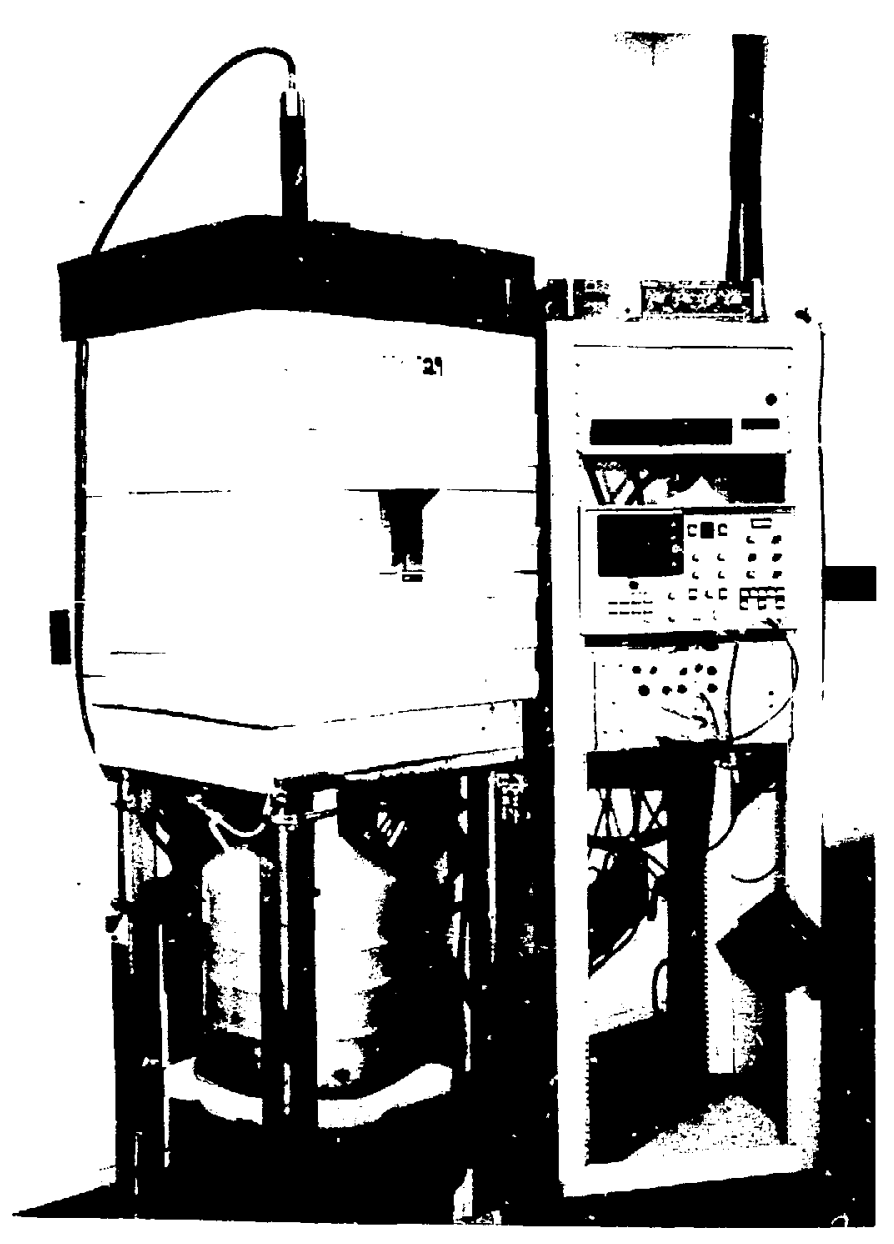

Fig. 10a.

$\mathrm{Ge}(\mathrm{Li})$ well detector with anticoincidence shield. 


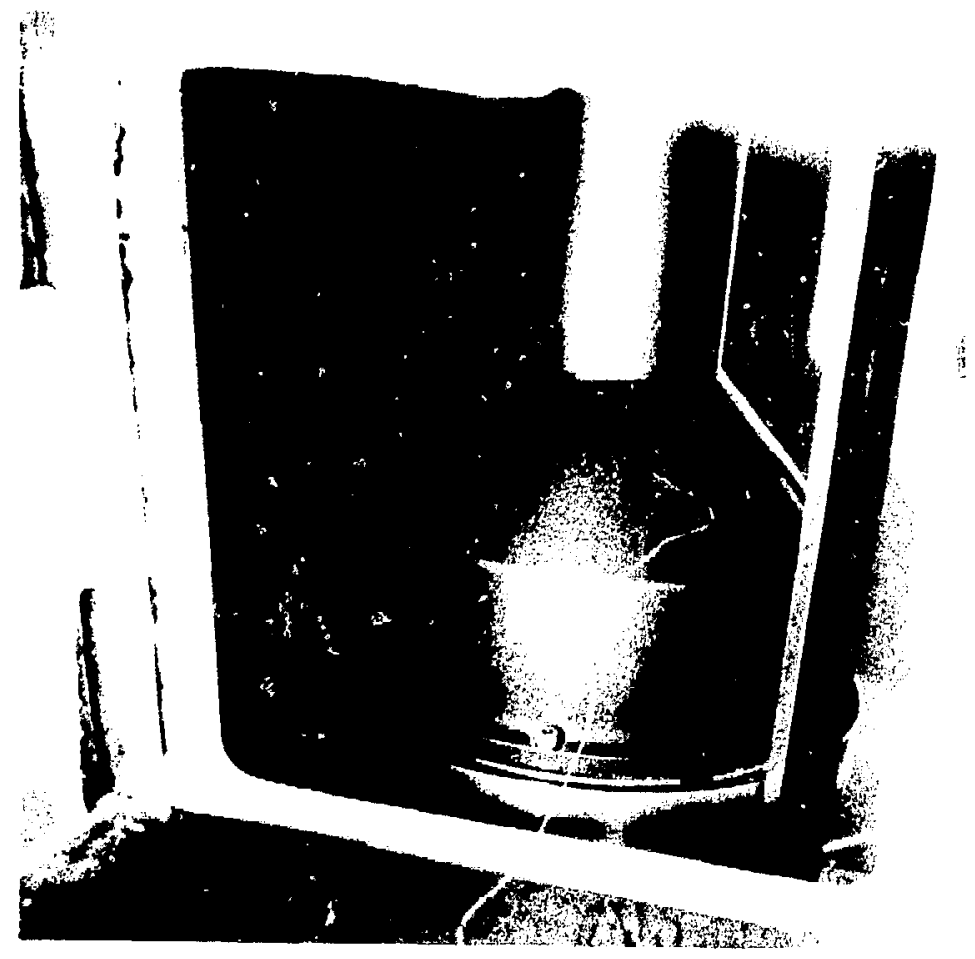

Fig. $10 b$.

Close-up of the anticoincidence shield for the Ge(Li) well detector.

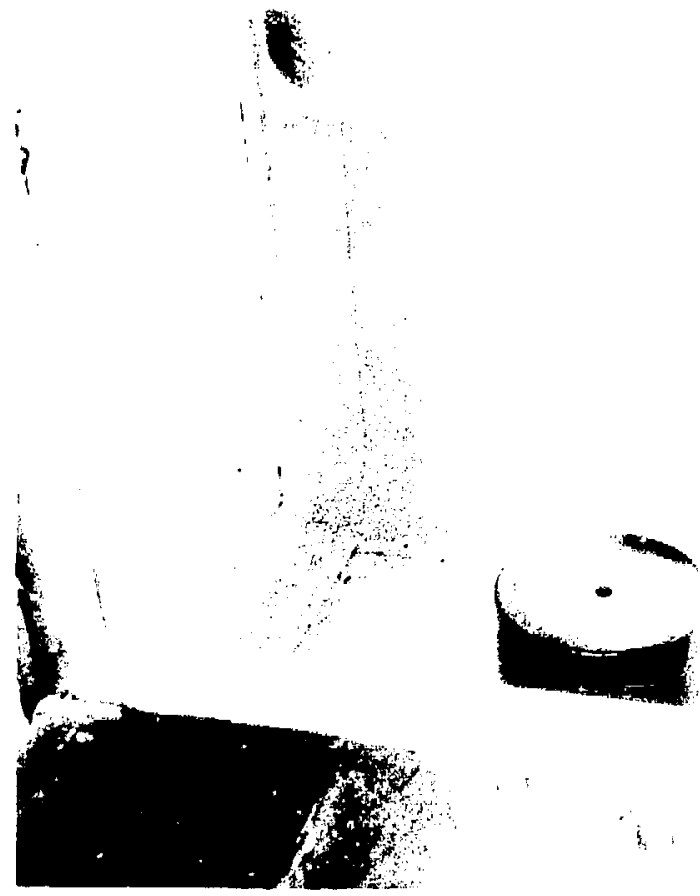

Fig. 11.

Anticoincidence shield of the well detector in the raised posi. tion. 


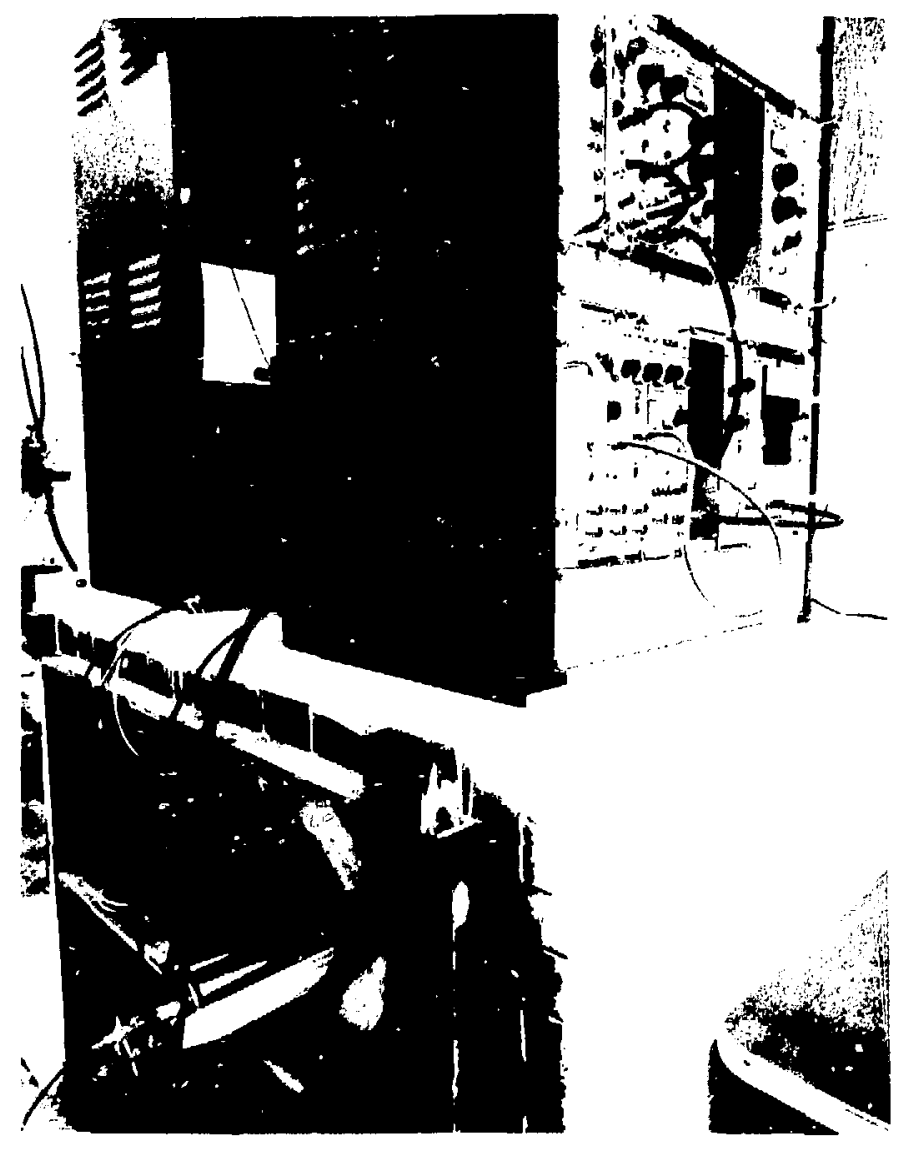

Fig. $12 a$.

Low-level ${ }^{\text {s" }} \mathrm{Ar}$ and ${ }^{3} \mathrm{H}$ proportional counting system.

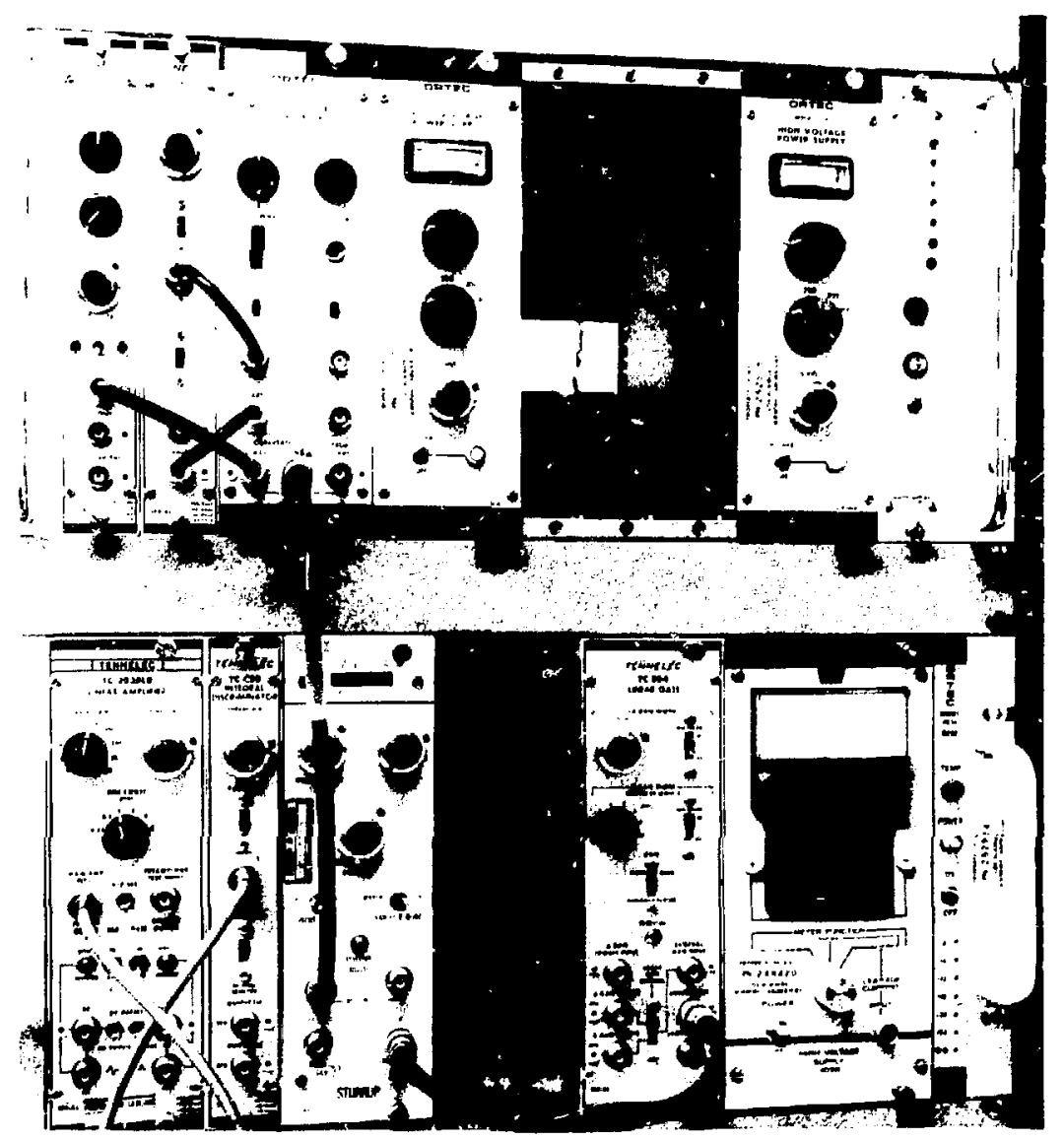

Fig. $12 b$

Electronics of the lou-level ${ }^{37} A r$ and ${ }^{3} H$ counting system. 


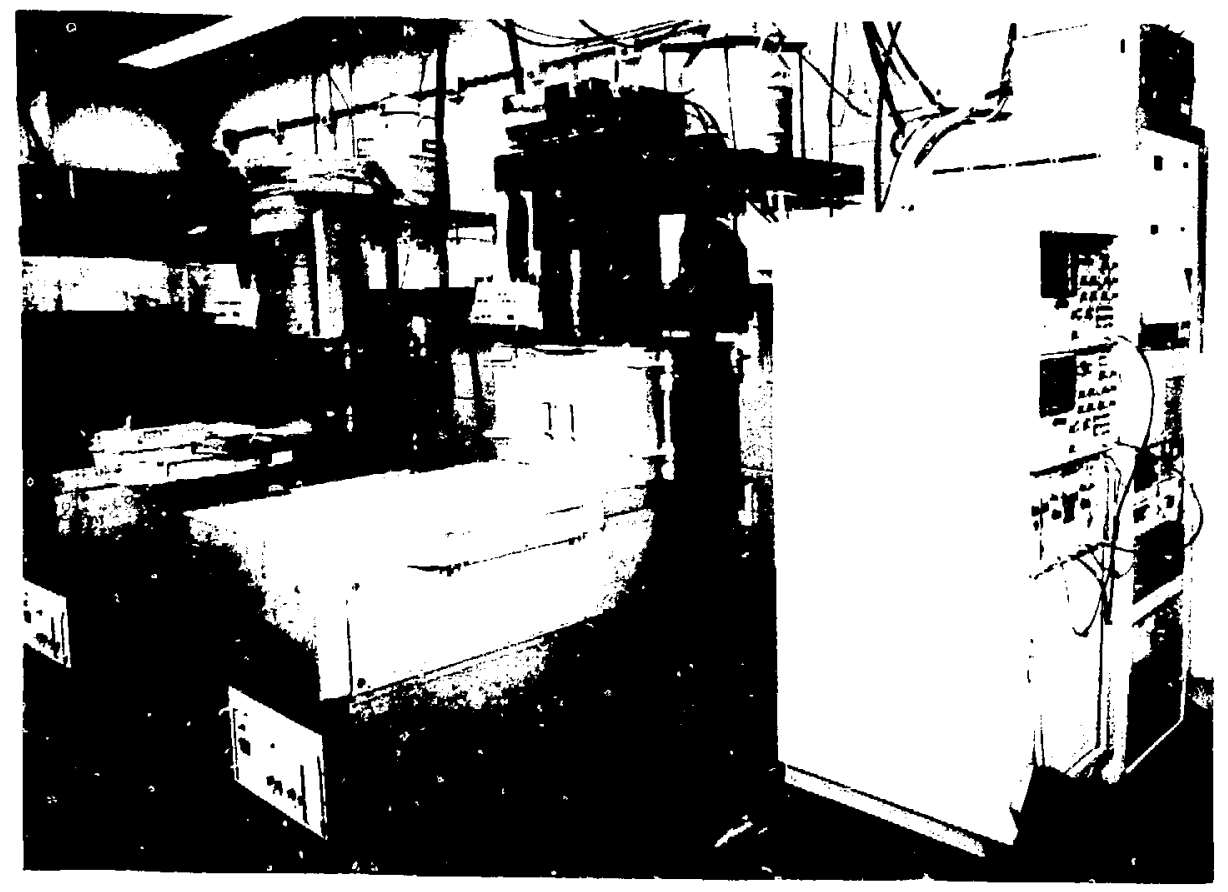

Fig. 13.

Automatic sample changers for Ge(Li) gamma spectroscopy.

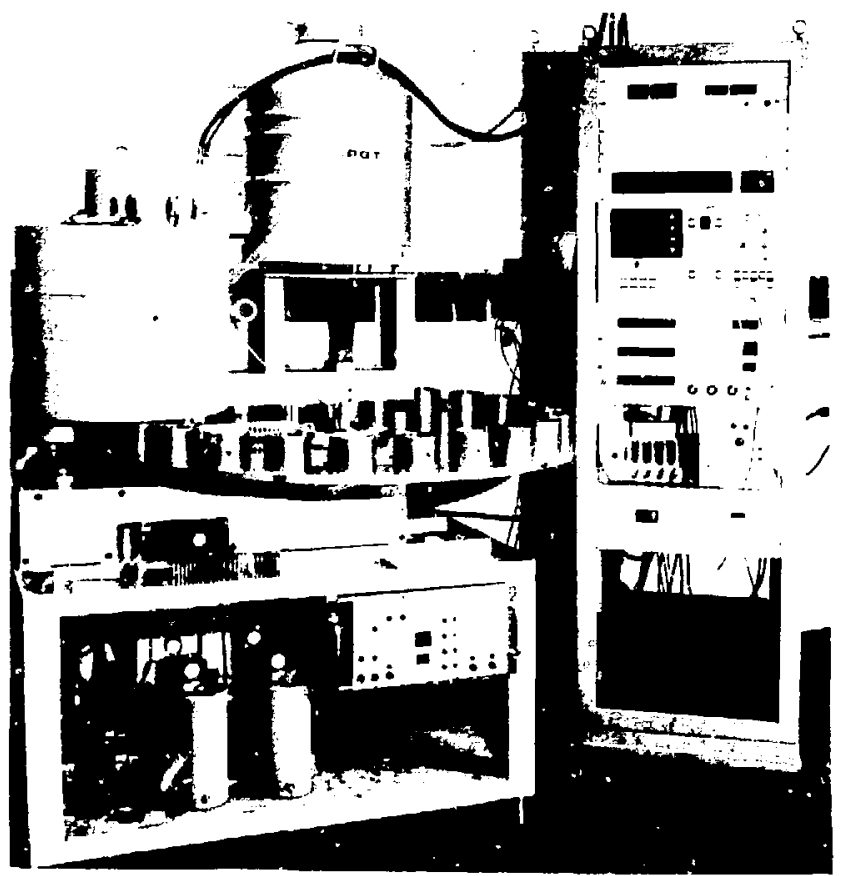

Fig. 14.

Automatic sample changer (wheel type) for Ge(Li) gamma spectroscopy. 


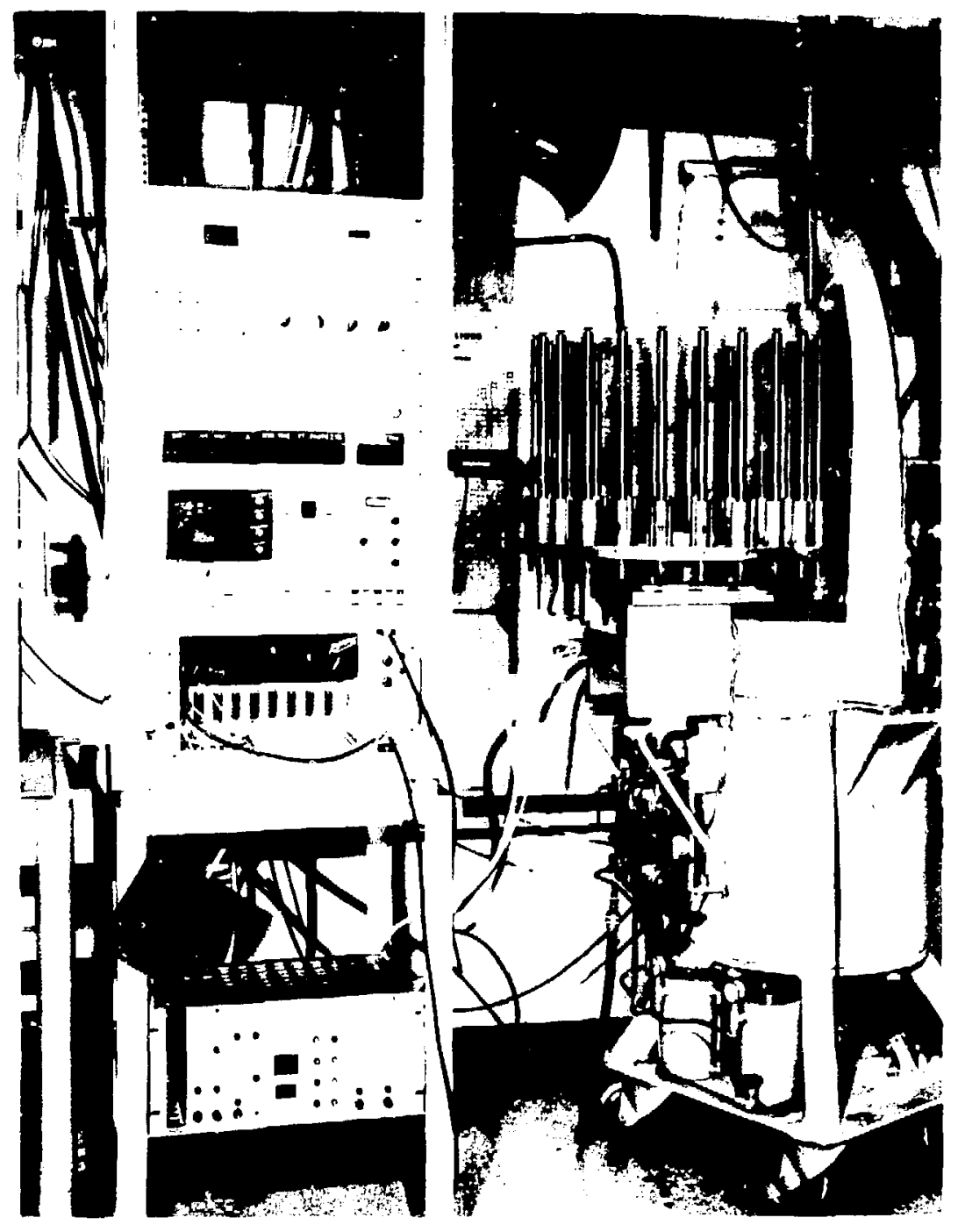

Fig. 15. 